\title{
Willy the Kid and Wonder Vag teach teens online about sexual health
}

Published at www.cmaj.ca on Mar. 30

$\mathrm{F}$ acing rising rates of sexually transmitted diseases among people aged 15 to 24 , the Middlesex-London Health Unit in London, Ontario, wanted to develop a novel and fun way of educating teens and young adults about sexual health.

Their solution?

"Adventures in Sex City," an online game developed by youth for youth, in which a "Sex Squad" of cartoon superheroes - Captain Condom, Power Pap, Willy the Kid and Wonder Vag - battle the evil Sperminator, who is bent on infecting the good residents of the city. By correctly answering sexual health questions, players can conquer Sperminator, while being instructed by Myth Maniac, the squad's mysterious ally, about healthy sex (www.getitonlondon.com).

The response has been immense. In six weeks, the site received 275186 visits from nearly 180 countries.

"We didn't anticipate how much response there would be to the game and we're really pleased," says Dr. Bryna Warshawsky, the unit's associate medical officer of health. In aftergame surveys, $76 \%$ of participants reported that they had learned from playing and $81 \%$ would recommend it to others. "That would indicate, at least in terms of knowledge, it is having an impact."

Shelby Sandford, a 14-year-old student at Parkside Collegiate in St. Thomas, Ontario, found that the game "made an awkward topic not awkward."

Fellow Parkside student Martin Vandenberk, 16, found it "quite comical, but in a serious sense. Rather than being a joke, it was funny but informative at the same time. ... I laughed a lot." Vandenberk found he didn't always know the correct answers. For example: "Cold sores on the mouth can be spread through oral sex."

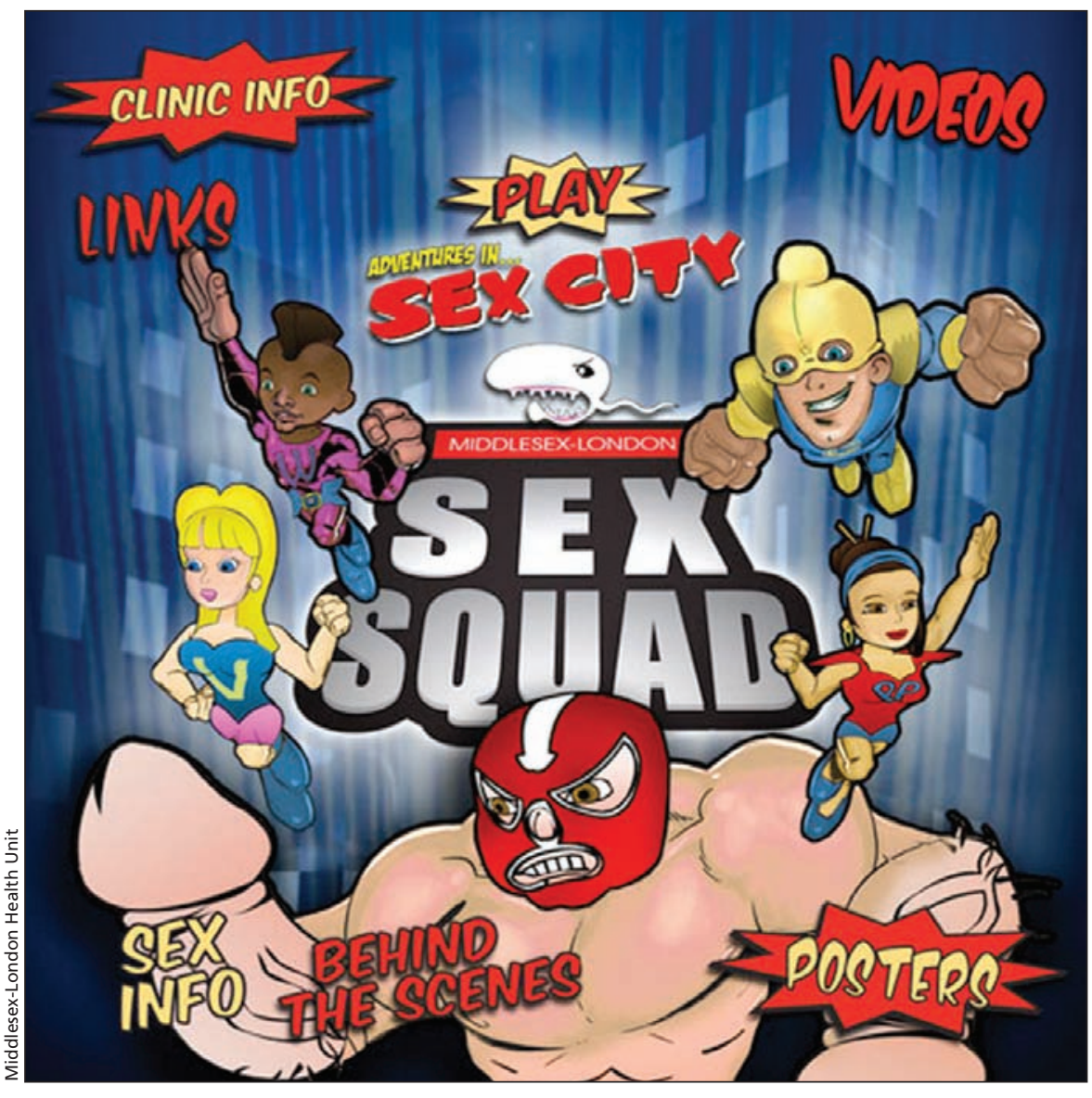

In the online game "Adventures in Sex City," a "Sex Squad" of cartoon superheroes Captain Condom, Power Pap, Willy the Kid and Wonder Vag - battle the evil Sperminator, whose is bent on infecting the good residents of the city.

Not all teens have responded with positive reviews, though. A 14-year-old wrote in a letter to the London Free Press that the game was "disgusting" and promoted sex before marriage. "Safe sex is no sex, simple as that," he concluded.

Sandford, along with another Parkside student, Emma Barrett, see a value, although they're concerned that female characters are "long-legged and thin-waisted" and are not reflective of average girls or women. The pair say they obtained new information about the morning-after pill and would like to see the game introduced in health or physical education courses. "It's kind of cool that you can make it fun, but it's still informative," Barrett says.

The Thames Valley District School Board has commenced using the game in teaching sexual health but the London District Catholic School Board has opted not to do so because "through faith development and formation," Catholic students are taught the human body is sacred and a gift from God and should be treated with the utmost respect, says Wilma de Rond, the board's director of education. "Sexuality is a great and powerful gift. Sexual activity is appropriate only within the sacrament of marriage." 
"We know the game isn't for everybody," says Warshawsky. "For the people who it helps break the ice or initiates the conversation or just helps to provide the information in a way people can access it, then it's been useful. Not everybody will like this method of teaching sexual health. ... It's a bit on the edge and it's quite different."

Academic experts say it may have value. Dr. Miriam Kaufman, a pediatrician in Toronto, Ontario, likes "the layering of this site" and the opportunity for teens to play an amusing game while receiving accurate information about sexual health. But she's disap- pointed there are no resources on sex and disabilities on the site.

While many may only play the game once, they "might be more likely" to return for facts when seeking further information, Kaufman adds. But she's reluctant to predict the impact on behaviour, saying that is "anyone's guess. It would be great to have some research to see if there is an effect."

Kaufman believes that other physicians who work with teens will recommend the site, while Warshawsky says physicians could use it to help parents bridge communications with their offspring about sexual health.

Physicians should use it, says
Francesca Geddes, a 19-year-old University of Western Ontario student who helped develop the game along with eight other youths brought together by Mind Your Mind, a London-based mental health organization. "It would show they know what's hip and new with the kids. ... It would show they're looking at new ways to teach young people."

Geddes is elated with the controversy that surrounds the game and hopes that will encourage people to be more cautious and "go get tested regularly." Lynne Swanson, London, Ont.

DOI:10.1503/cmaj.109-3217 